\title{
A sponge-like small pore zeolite with great accessibility to the micropores
}

Received 00th January 20xx, Accepted 00th January 20xx DOI: $10.1039 / x 0 x x 00000 x$

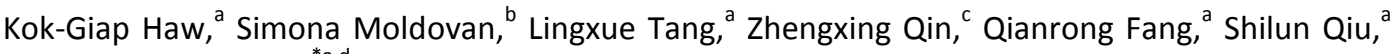 \\ and Valentin Valtchev ${ }^{* a, d}$
}

\begin{abstract}
Small pore zeolites, due to pore size constraint, have limited applications. Post-modification on the materials is therefore important to widen their use. A CHA-type zeolite (SSZ-13) with unique sponge-like structure is obtained by fluoride leaching. The development of macroporosity started from the crystal surfaces and continued progressively into the crystal by prolonging treatment. Nitrogen physisorption measurements showed an increase in micropore volume and specific surface area as a consequence of the dissolution of low crystalline part of the zeolite. The impact of etching on the accessiblity through the pore network, evaluated by means of breakthrough experiments of $\mathrm{CO}_{2} / \mathrm{N}_{2}$ and $\mathrm{CO}_{2} / \mathrm{CH}_{4}$ binary mixtures, showed an improved accessibility thanks to the interconnected macropores which shortens the diffusion pathlength. The set of experimental data shows the sponge-like SSZ-13 crystals retaining the intrinsic zeolitic properties but having improve accessibility and crystallinity.
\end{abstract}

\section{Introduction}

SSZ-13 is an aluminosilicate zeolite with CHA-type topology. ${ }^{1}$ The zeolite has attracted considerable attention thanks to its important application in selective catalytic reduction of nitrogen oxides $\left(\mathrm{NO}_{\mathrm{x}}\right)^{2}{ }^{2}$ and potential applications in methanol to olefins process (MTO), ${ }^{3}$ methylation of ethylene to propylene (ETP), ${ }^{4,5}$ and $\mathrm{CO}_{2}$ storage. ${ }^{6,7}$ The 3-dimensional pore system in SSZ-13 consists of large cavities ( $7.3 \times 12 \AA)$ that are connected by a small $8 \mathrm{MR}$ window $(3.8 \times 3.8 \AA)$. These small pore openings allow only small molecules to diffuse through the pores with an excellent product shape selectivity. Thus the small pore zeolite, i.e. SSZ-13, is particularly appropriate for the reactions such as $\mathrm{NH}_{3}-\mathrm{SCR}$ and $\mathrm{MTO}$ in respect to the medium (ZSM-5) and large (Mordenite) pore zeolites. ${ }^{8,9}$ However, it is very often that during a catalytic reaction the benefit of small pores in SSZ-13, i.e. the shape selectivity, is at the expense of its accessibility, thereby limiting the physical transport of reactants to the active sites. ${ }^{10}$ Gao et al. found that the diffusion limitations play a significant role in the $\mathrm{Cu}$ SSZ-13's catalytic performance. ${ }^{11}$ It is even worse in a micron

\footnotetext{
a. State Key Laboratory of Inorganic Synthesis and Preparative Chemistry, Jilin University, Changchun 130012, China

${ }^{b}$. Institut des Sciences Appliquées de Rouen, Rouen University, Groupe de Physique des Matériaux (GPM), 76801 Rouen, France

c. State Key Laboratory of Heavy Oil Processing, College of Chemical Engineering,

China University of Petroleum (East China), 266580 Qingdao, China

d. Normandie Univ, ENSICAEN, UNICAEN, CNRS, Laboratoire Catalyse et

Spectrochimie, 6 Marechal Juin, 14050 Caen, France

E-mail: valentin.valtchev@ensicaen.fr

Electronic Supplementary Information (ESI) available: [details of any supplementary information available should be included here]. See
} DOI: $10.1039 / x 0 x x 00000 x$ size zeolite catalyst since only a minor fraction of the zeolites' active volume is being used in catalysis. Hierarchical zeolites which couple secondary network of meso- and macropores to the micropores could potentially solve the problem by enhancing the accessibility and thereby catalytic effectivity of the active sites in the zeolite crystal. It is thus important to enhance their mass transport properties.

Secondary pores, i.e. meso- or macro-pores, in zeolites can be introduced either by post-synthesis methods or in-situ during crystal growth. By introducing secondary pores to these microporous materials, the transport of molecules through the catalytically active sites is enhanced and their catalytic performance is improved. ${ }^{12,13}$ Soft and hard templating routes are commonly used for in-situ introduction of secondary porosity. Depend on the target application, the secondary pores as well as the physicochemical properties of zeolites, could be customized during post-synthesis modification either by steaming and acid or alkaline leaching.

Neutral pH etchant is employed when milder leaching is required. Neutral etching has the advantages of being environment friendly, easy to control and safe to handle. One of the most widely used neutral etchant is ammonium fluoride. ${ }^{14}$ It was shown recently that post-treatment in ammonium fluoride solution allows the unbiased extraction of T-atoms from the pore system of a large pore FAU-type zeolite and generated additional microporous space thanks to the opening of sodalite cages. ${ }^{15}$ The ammonium fluoride treatment was also successfully used to generate mesopores in medium (ZSM-5) and large (Mordenite) pore pentasil type zeolites. ${ }^{16,17}$ Present study reports on the preparation of SSZ-13 zeolite with sponge-like morphology by neutral etching in the presence of ammonium fluoride and hydrogen peroxide. Depending on the 
treatment procedure different type (meso- or macro-) of secondary pores are generated. The advantage of generating macropores is the ability to remedy the mass transport limitation in zeolites without introducing large external surface area. ${ }^{18} \mathrm{NH}_{4} \mathrm{~F}$ is the only known to date etchant that allows unbiased chemical extraction of the framework T-atoms from a zeolite framework. The use of hydrogen peroxide in conjunction will accelerate the etching. ${ }^{14}$

Herein, we developed a post-synthesis modification leading to unique sponge-like SSZ-13 crystals retaining the intrinsic zeolitic properties, but having an improve accessibility. The ultimate goal of the study is to develop a general approach to make any type of zeolite hierarchical and to improve their performance in different applications. We investigated the effect of the combined $\mathrm{NH}_{4} \mathrm{~F}-\mathrm{H}_{2} \mathrm{O}_{2}$ etching of SSZ-13 by various characterization techniques such as powder $\mathrm{X}$-ray diffraction, nitrogen physisorption, SEM, TEM, and NMR. Furthermore, the effect of etching towards diffusion properties of SSZ-13 is determined by the separation of binary mixtures of $\mathrm{CH}_{4} / \mathrm{CO}_{2} / \mathrm{He}(25 / 25 / 50)$ and $\mathrm{N}_{2} / \mathrm{CO}_{2} / \mathrm{He}(25 / 25 / 50)$ gases in breakthrough experiments.

\section{Experimental}

\section{Materials}

All chemicals and materials were purchased from commercially available sources and used without further purification. Potassium hydroxide ( $\mathrm{KOH} 98 \%$, Aladdin Chemistry), aluminum isopropoxide (98\%, Sigma Aldrich), fumed silica $\left(\mathrm{SiO}_{2}\right.$, Sigma Aldrich), N,N,N-trimethyl-1-adamantammonium (TMAD 98\%, Aladdin Chemistry), tetraethylammonium hydroxide (TEAOH 20 wt\% in water, Sigma Aldrich), phosphoric acid (85\% aqueous solution, Sigma Aldrich), deionized water, sodium nitrate $\left(99.5 \%\right.$, Aladdin Chemistry), hydrogen peroxide $\left(\mathrm{H}_{2} \mathrm{O}_{2}\right.$ 30 wt\% in water, Aladdin Chemistry), and ammonium fluoride $\left(\mathrm{NH}_{4} \mathrm{~F} 98 \%\right.$, Sigma Aldrich). Zeolite beta with $\mathrm{Si} / \mathrm{Al}=15$ was purchased from Changchun Third Party Pharmaceutical Technology and used as silica-alumina source in the synthesis of SSZ-13.

\section{Synthesis of SSZ-13}

SSZ-13 was synthesized by interzeolite conversion of zeolite Beta in the presence of N,N,N-trimethyl-1-adamantammonium (TMAD) as a structure directing agent, reported elsewhere. ${ }^{19}$ The molar composition of the initial gel was $0.236 \mathrm{TMAD}: 0.5 \mathrm{KOH}: 30 \mathrm{H}_{2} \mathrm{O}$. Zeolite Beta was used as silicon and aluminum source and no additional $\mathrm{Si}$ or $\mathrm{Al}$ was added to the starting mixture. In a typical experiment, $1.7 \mathrm{~g}$ zeolite beta was added to a solution containing $0.60 \mathrm{~g} \mathrm{KOH}, 1.94 \mathrm{~g} \mathrm{TMAD}$, $14.82 \mathrm{~g} \mathrm{H}_{2} \mathrm{O}$ and stirred for $2 \mathrm{~h}$ at room temperature. The final molar composition of the gel after the addition of zeolite beta was 0.236TMAD:0.5KOH: $1 \mathrm{SiO}_{2}: 0.032 \mathrm{Al}_{2} \mathrm{O}_{3}: 30 \mathrm{H}_{2} \mathrm{O}$.

After homogenization, the mixture was transferred to Teflonlined stainless-steel autoclave. The hydrothermal synthesis was carried out at $150{ }^{\circ} \mathrm{C}$ for $24 \mathrm{~h}$. After crystallization step, the solid product was collected by vacuum filtration and washed thoroughly with deionized water until a near neutral
$\mathrm{pH}$ and dried overnight at $60{ }^{\circ} \mathrm{C}$. The as-synthesized SSZ-13 sample was calcined at $600{ }^{\circ} \mathrm{C}$ (at $100{ }^{\circ} \mathrm{C} \cdot \mathrm{h}^{-1}$ ramp) in air flow for $10 \mathrm{~h}$.

\section{Preparation of sponge-like SSZ-13}

$\mathrm{NH}_{4} \mathrm{~F}$ solution ( 40 wt\%, aq.) was prepared by dissolving $4.0 \mathrm{~g}$ of $\mathrm{NH}_{4} \mathrm{~F}$ in $3.0 \mathrm{~g}$ of $\mathrm{H}_{2} \mathrm{O}$ and $3.0 \mathrm{~g}$ of $\mathrm{H}_{2} \mathrm{O}_{2} .0 .3 \mathrm{~g}$ of SSZ-13 was then added into the $\mathrm{H}_{2} \mathrm{O}_{2}-\mathrm{NH}_{4} \mathrm{~F}$ solution. The zeolite treatment was performed at $20{ }^{\circ} \mathrm{C}$ under ultrasonic radiation for $\mathrm{t}=15$, $30,60,90,120$, and 180 min respectively. The heat from the radiation was compensated by adding ice into the ultrasonic bath and the temperature was maintained at $20 \pm 2{ }^{\circ} \mathrm{C}$. The samples were rinsed thoroughly with deionized water under vacuum filtration and dried overnight at $60{ }^{\circ} \mathrm{C}$. The effect of $\mathrm{H}_{2} \mathrm{O}_{2}$-assisted etching was compared with the sole $\mathrm{NH}_{4} \mathrm{~F}$ treatment under the same conditions. The samples obtained were denoted as $\mathrm{H}_{2} \mathrm{O}_{2}-\mathrm{NH}_{4} \mathrm{~F}$ USt and $\mathrm{NH}_{4} \mathrm{~F}$ USt, where $\mathrm{t}$ is the time in minutes.

For comparison purposes, etching of SSZ-13 in an acidic etchant $\mathrm{HCl}(0.5 \mathrm{M})$, and an alkaline etchant $\mathrm{NaOH}(0.5 \mathrm{M})$, was performed. $0.3 \mathrm{~g}$ of SSZ-13 was added into $10 \mathrm{~g}$ of the corresponding acid or alkaline solutions. Etching was performed at $20{ }^{\circ} \mathrm{C}$ under ultrasonic (US) radiation for $\mathrm{t}=30$ and $60 \mathrm{~min}$. The heat from the radiation was compensated by addition of ice into the ultrasonic bath and the temperature was maintained at $20 \pm 2{ }^{\circ} \mathrm{C}$. The samples were rinsed thoroughly with deionized water under vacuum filtration and dried overnight at $60{ }^{\circ} \mathrm{C}$. The samples obtained were denoted as $\mathrm{HCl}$ USt and $\mathrm{NaOH}$ USt respectively, where $\mathrm{t}$ is the time in minutes.

\section{Characterizations}

All materials were characterized by X-ray diffraction (XRD) using a PANalytical B.V. Empyrean powder diffractometer with Cu $K_{\alpha}$ radiation $(\lambda=1.5418 \AA$ ) operating at $40 \mathrm{kV}$ and $40 \mathrm{~mA}$. The samples were scanned in the $2 \theta$ range of $4-40^{\circ}$ with a step size of $0.02^{\circ}$. Scanning electron microscopy (SEM) micrographs were taken on a JEOL JSM7400F microscope operated at $15 \mathrm{kV}$ and JEOL JSM-7900F microscope operated at $1 \mathrm{kV}$. Before measurement, the sample was placed on a sample holder, coated with isopropyl alcohol-based carbon conductive adhesive. Transmission electron microscopy (TEM) analysis was performed on a JEOL JEM-2100F. Prior to the measurement, a diluted colloidal suspension of sample was sonicated for $5 \mathrm{~min}$ and then dropped on a carbon-filmcovered 300-mesh copper electron microscope grids and dried. Tomography study was performed using a JEOL JEM2100F TEM equipped with a high-resolution objective lens pole piece at $200 \mathrm{kV}$. The tomography series were acquired between tilting angles of $\pm 70^{\circ}$ with a $2^{\circ}$ Saxton scheme and the subsequent series alignments were performed with the IMOD software using Au nanoparticles $(5-7 \mathrm{~nm})$ as fiducial markers. To resolve details at maximum resolution we used the SIRT algorithm implemented in fast software running on multicore computers, Tomo3D. The size of the TEM projections used for the reconstruction was $2 \mathrm{k} \times 2 \mathrm{k}$ pixels. Nitrogen physisorption measurements were performed on a Micromeritics ASAP 2040 
surface area analyzer. The calcined samples were analyzed after degassing at $300{ }^{\circ} \mathrm{C}$. The specific surface areas $\left(S_{\mathrm{BET}} / \mathrm{m}^{2}\right.$ $\mathrm{g}^{-1}$ ) were obtained using the Brunauer-Emmett-Teller (BET) equation. The microporous volume $\left(V_{\text {micro }} / \mathrm{cm}^{3} \mathrm{~g}^{-1}\right)$ was obtained from t-plot based on the Harkins-Jura equation. The pore size distribution and total pore volume $\left(V_{\mathrm{T}} / \mathrm{cm}^{3} \mathrm{~g}^{-1}\right)$ was obtained from the desorption branch using the Barrett-JoynerHalenda (BJH) algorithm assuming cylindrical pores. NMR measurements were done with 4-OD $\mathrm{mm}$ zirconia rotors and with a spinning speed of $12 \mathrm{kHz}$. Magic angle spinning nuclear magnetic resonance (MAS NMR) ${ }^{27} \mathrm{Al}$ and ${ }^{29} \mathrm{Si}$ spectra were recorded on a Bruker Avance 500 spectrometer operating at $130.3 \mathrm{MHz}$, with a $\pi / 12$ pulse and a recycle delay of $1 \mathrm{~s}$. $\mathrm{Al}\left(\mathrm{NO}_{3}\right)_{3} 1 \mathrm{M}$ was used as a reference for ${ }^{27} \mathrm{Al}$. Elemental analysis of the sample was measured by Energy Dispersive XRay Fluorescence Spectrometer (EDX) operated under TEM (JEM-2100F).

\section{Breakthrough experiment}

Na-exchanged SSZ-13 samples were used in breakthrough experiments. The samples were ion exchanged with $0.3 \mathrm{M}$ $\mathrm{NaNO}_{3}$ solution (solid:liquid $=1: 100$, weight ratio) twice. Breakthrough experiments were performed with binary mixtures of $\mathrm{CH}_{4} / \mathrm{CO}_{2} / \mathrm{He} \quad(25 / 25 / 50)$ and $\mathrm{N}_{2} / \mathrm{CO}_{2} / \mathrm{He}$ $(25 / 25 / 50)$, respectively. The gas mixtures were equilibrated at $25{ }^{\circ} \mathrm{C}$ with a residence time of $5 \mathrm{~h}$ before the measurement. A $4.32 \mathrm{~mm}$ diameter stainless steel adsorption column with a length of $10 \mathrm{~cm}$ packed with approximately $0.8 \mathrm{~g}$ of sample. Prior to the measurements, the adsorbent was purged with a pure $\mathrm{He}(10 \mathrm{ml} / \mathrm{min})$ through the column at $25{ }^{\circ} \mathrm{C}$ with a residence time of $5 \mathrm{~h}$. Breakthrough experiments were performed at $25{ }^{\circ} \mathrm{C}$ with the flow of feed gas at $0.1 \mathrm{MPa}$ of pressure and $8 \mathrm{ml} / \mathrm{min}$ of flow rate.

\section{Results and discussion}

Homemade rectangular SSZ-13 crystals with dimension between 2 to $5 \mu \mathrm{m}$ are used as the precursor. The parent SSZ13 exhibits high $\mathrm{X}$-ray crystallinity without traces of concurrent phases (Fig. 1). An increase in crystallinity is observed on the samples after treatment. Such increase in the crystallinity is attributed to the removal of the amorphous and/or low crystalline part of the sample. The crystallinity of the samples

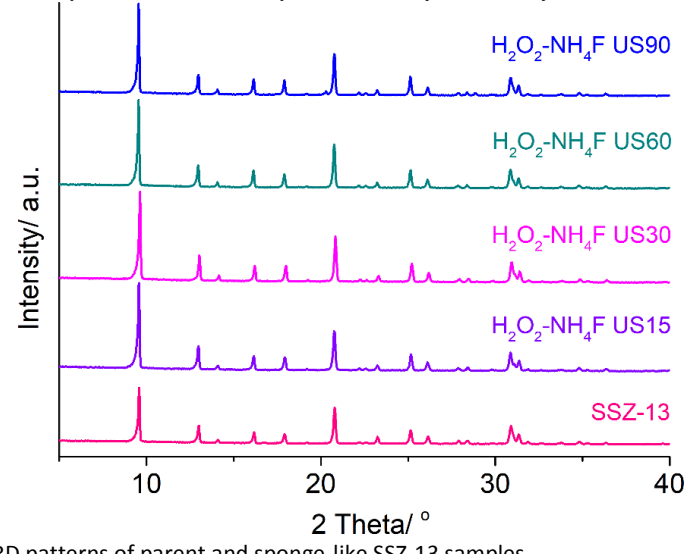

Fig. 1 XRD patterns of parent and sponge-like SSZ-13 samples.
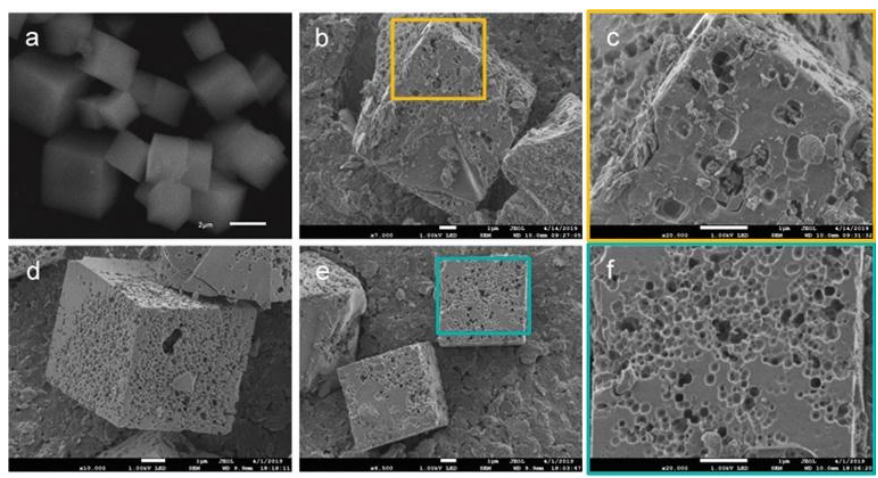

Fig. 2 SEM micrographs of parent SSZ-13 (a), general and magnified view of $\mathrm{NH}_{4} \mathrm{~F}$ US60 $(b, c)$ and $\mathrm{H}_{2} \mathrm{O}_{2}-\mathrm{NH}_{4} \mathrm{~F}$ US60 (d, e, f). Inset showed the region magnified in $\mathrm{c}$ and $\mathrm{f}$.

is retained even after 90 min of treatment showing that the zeolite structure is stable during prolonged treatment. SEM micrograph of the parent SSZ-13 shows individual rectangular shape crystals with 2-5 micron in diameters and welldeveloped crystal faces (Fig. 2a). SEM inspection of the treated samples shows changes in surface morphology (Fig. 2b). Rectangular pores with straight edges are developed on the crystal faces. These pores are attributed to the dissolution of the nano crystalline domains. ${ }^{20}$ The interface between the coherent crystalline domains and between crystals represents a zone with high concentrations of structural defects, which is more vulnerable to chemical attack. Thus a mosaic structure of rectangular shaped pores is formed upon unbiased dissolution with the $\mathrm{NH}_{4} \mathrm{~F}$ etching solution. An increase in the etching time leads to the formation of larger and deeper pores with retaining rectangular shape since the dissolution rate is similar in different crystallographic directions (Fig. S1 and S2). The size of these secondary pores varies between 50 and $500 \mathrm{~nm}$. The final stage of this process is desegmentation of the zeolite crystals into much smaller particles (Fig. S1e,f). The treatment in the presence of hydrogen peroxide (Fig. $\mathbf{2 f}$ ) is more intense than the sole use of $\mathrm{NH}_{4} \mathrm{~F}$ (Fig. 2c). We interpret the higher concentration of pores as aggressive etching in the presence of $\mathrm{H}_{2} \mathrm{O}_{2}$ with the potential to generate secondary pores from the smallest surface imperfections. The pores penetrate deeply in the bulk of the crystals, giving an open structure with spongelike appearance which differs from the smooth crystal surface of the pristine SSZ-13, as illustrated under SEM and TEM (Fig. 3). A careful inspection on the TEM tomography showed that these macropores are well connected (Fig. S3). A good connectivity between macropores is an important criterion in zeolite catalyst thanks to its exceptional accessibility.

Nitrogen adsorption-desorption analysis of SSZ-13 samples showed Type I isotherms with a sharp uptake at a low pressure of $\mathrm{P} / \mathrm{P}_{0}<0.05$, which is characteristic of microporous materials (Fig. S4). The $S_{\text {BET }}$ and $V_{\text {mic }}$ of the $\mathrm{NH}_{4} \mathrm{~F}$ treated samples are in good agreement to the XRD analyses (Table S1). Micropore volume is an important characteristic of zeolite-type materials which relates to their crystallinity. For instance, an increase in the $S_{\mathrm{BET}}$ and $V_{\text {mic }}$ in the treated sample is attributed to the elimination of low crystalline phase from SSZ-13 which increases their crystallinity. The absence of hysteresis loop 
(Fig. S4) indicates the pores generated are macropores with pore

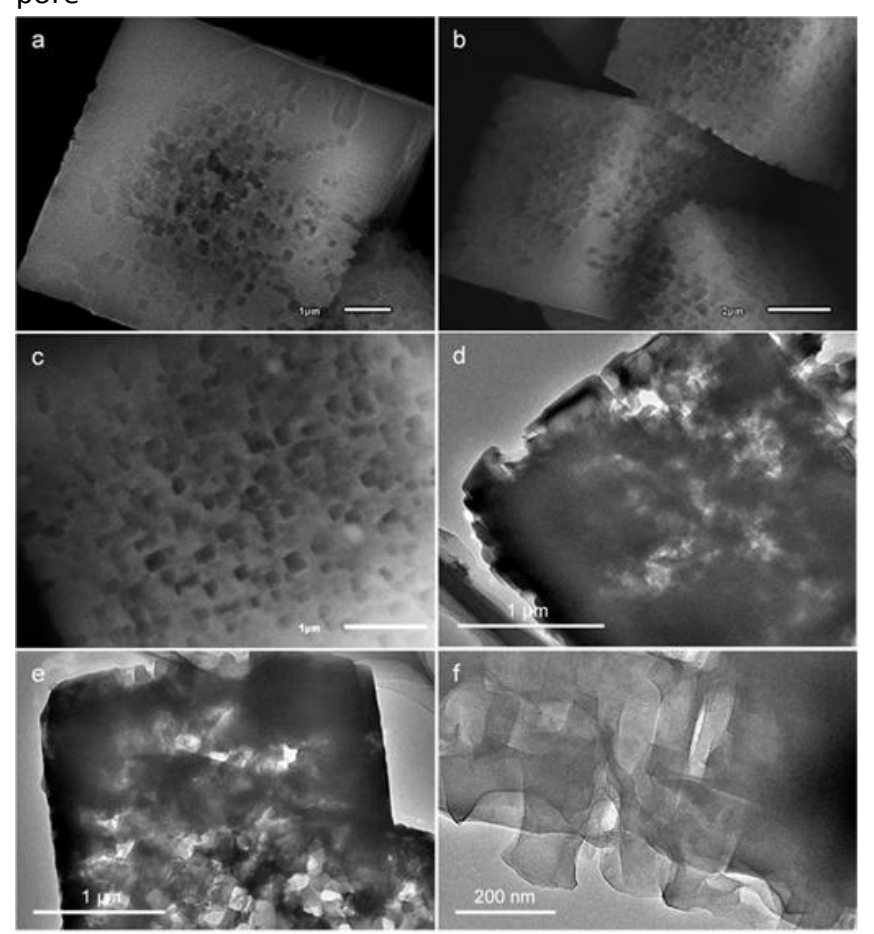

Fig. 3 SEM $(a, b, c)$ and TEM $(d, e, f)$ micrographs showing the mosaic structure $(a, d, e)$ and sponge-like structure (b,c,f) of sample $\mathrm{H}_{2} \mathrm{O}_{2}-\mathrm{NH}_{4} \mathrm{~F}$ US9O.

diameter $>50 \mathrm{~nm}$, which is in good agreement to TEM and SEM observations. This conclusion is supported by negligible increase of the total pore volume, $V_{\mathrm{T}}$ which is due to the fact that $\mathrm{N}_{2}$ adsorption analysis is not appropriate for studying macroporous materials. The Si/Al ratio of the parent SSZ-13 sample is 7.8 according to the ICP analysis (Table S1). Since $\mathrm{NH}_{4} \mathrm{~F}$ treatment is non-chemically selective the elemental compositions of the treated samples (i.e. Si/Al ratio) are retained.

In comparison, both $\mathrm{HCl}$ and $\mathrm{NaOH}$ treated samples showed significant drop in crystallinity as shown in XRD patterns and nitrogen physisorption (Fig. S5 and S6). Both caustic and acid treatments are effective in desilication and dealumination as shown in EDX analysis (Table S2) but not effective in generating sponge-like SSZ-13 as shown in nitrogen physisorption (Table S2), and SEM investigation (Fig. S7).

The yield and weight loss of SSZ-13 after $\mathrm{NH}_{4} \mathrm{~F}, \mathrm{H}_{2} \mathrm{O}_{2}, \mathrm{NaOH}$ and $\mathrm{HCl}$ treatments at different time intervals are summarized in Table S3. Highest weight loss is recorded on the $\mathrm{NH}_{4} \mathrm{~F}$ treated sample due to the formation of sponge-like structure. In sole use of hydrogen peroxide, $8 \%$ of weight loss is recorded. Since no change of morphology is detected (vide supra SEM, TEM and $\mathrm{N}_{2}$ physisorption), such weight loss might attribute to the extraction of non-crystalline part of the sample. The same observations applied for $\mathrm{NaOH}$ and $\mathrm{HCl}$ treated samples since no changes in morphologies are observed.

${ }^{27} \mathrm{Al}$ and ${ }^{29} \mathrm{Si}$ MAS NMR analysis provides valuable information for the short range order in zeolite frameworks. The NMR spectra of the parent and the treated SSZ-13 samples are presented in Fig. 4. There is only single well-resolved signal at $48 \mathrm{ppm}$ in the ${ }^{27} \mathrm{Al}$ MAS NMR spectra (Fig. 4a) of the parent and treated samples attributed to tetrahedrally coordinated a

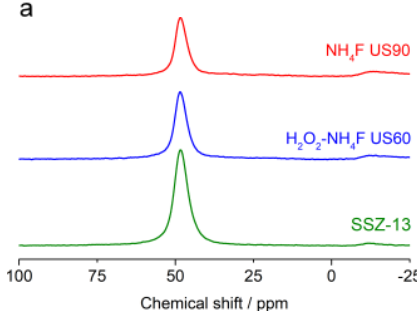

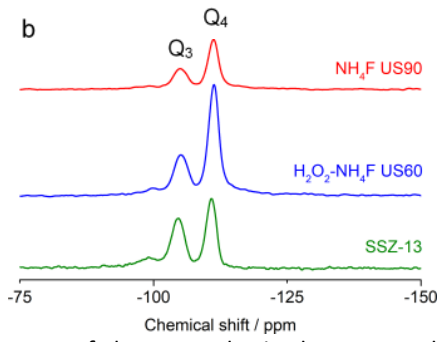

Fig. $4{ }^{27} \mathrm{Al}$ (a) and ${ }^{29} \mathrm{Si}$ (b) MAS NMR spectra of the as-synthesized parent and sponge-like SSZ-13 samples.

framework aluminum atoms, which evidences that $\mathrm{NH}_{4} \mathrm{~F}$ etching does not change the chemical environment in zeolite. The same conclusion can be drawn from the ${ }^{29} \mathrm{Si}$ MAS NMR spectra of parent and treated samples (Fig. 4b) where no substantial difference in the spectra between the parent and fluoride treated samples is detected. It should be emphasized that the proportion of $\mathrm{Q}_{3}$ species in both etched samples is lower than that of pristine zeolite. This indicates that some defective $\mathrm{Q}_{3}$ silanol sites, $\left[(\mathrm{HO}) \mathrm{Si}(\mathrm{OSi})_{3}\right]$ are removed during etching which gives rise to a much perfect crystals evidence by an increase proportion of peak area on $\mathrm{Q}_{4}$ silicon sites $\left[\mathrm{Si}(\mathrm{OSi})_{4}\right]$ to $\mathrm{Q}_{3}$ silanol species. Noteworthy, no extra framework $\mathrm{Al}^{\mathrm{VI}}$ species are present in the treated sample. It should be noted that non-zeolitic extra frameworks species with octahedrally coordinated Al structure are generally formed in zeolite micropores during conventional treatments with acid or base. ${ }^{21,22}$ Several negative effects such as a decrease in micropore volume, pore blocking and active sites deactivation are related to these extra framework species. In the case of $\mathrm{NH}_{4} \mathrm{~F}$, the etched $\mathrm{Si}$ - and $\mathrm{Al}$ - specie are soluble and easily remove by washing. In addition, the sponge-like structure will make the purification easier thanks to the improve accessibility.

The set of data show that the combined $\mathrm{H}_{2} \mathrm{O}_{2}-\mathrm{NH}_{4} \mathrm{~F}$ treatment provides similar results as the sole $\mathrm{NH}_{4} \mathrm{~F}$ etching in terms of retained chemical composition of parent zeolite and preferential dissolution of the low crystalline and highly faulted part of the crystals. The main difference is the morphological features of the generated macro-mesoporous channel system. The collected data show that in the presence of $\mathrm{H}_{2} \mathrm{O}_{2}$, the $\mathrm{NH}_{4} \mathrm{~F}$ dissolution starts from larger number of defect sites and the dissolution is faster than the sole use of $\mathrm{NH}_{4} \mathrm{~F}$. The synergy between the two etchant makes the process of zeolite dissolution much more efficient. This will allow also to decrease the amount of $\mathrm{NH}_{4} \mathrm{~F}$ employed and thus to make the treatment more economic and environmentally benign. Our interpretation is that hydrogen peroxide, as a powerful oxidant, prepare the surface T-atoms towards reaction with $\mathrm{NH}_{4} \mathrm{~F}$. The same reaction has been used for silicon etching in semiconductor industry. ${ }^{14}$ The mechanism involving hydrogen peroxide and $\mathrm{NH}_{4} \mathrm{~F}$ was reported elsewhere. ${ }^{14}$ Briefly, the reaction begins with the oxidizing agent (i.e. $\mathrm{H}_{2} \mathrm{O}_{2}$ ) reacts with silicon and forms silicon oxide 
intermediate, which then reacts with $\mathrm{NH}_{4} \mathrm{~F}$ and forms soluble hexafluorosilicates. The exposed silicon is consecutively oxidized to silicon oxide intermediate and reacts with $\mathrm{NH}_{4} \mathrm{~F}$. Thus, the etching proceeds spontaneously.

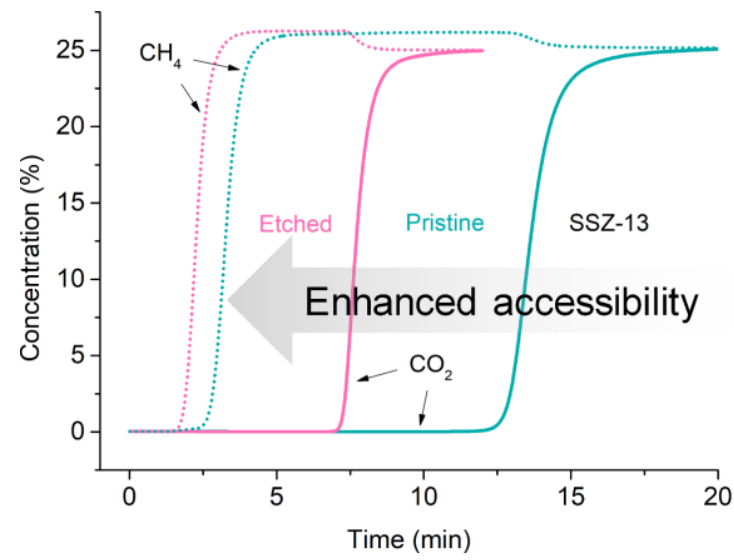

Fig. 5 Breakthrough curves of pristine and sponge-like SSZ-13 $\left(\mathrm{H}_{2} \mathrm{O}_{2}-\mathrm{NH}_{4} \mathrm{~F}\right.$ US60) in the presence of $\mathrm{CH}_{4} / \mathrm{CO}_{2}$ gas mixtures at $25^{\circ} \mathrm{C}$.

The performance of the sponge-like materials was analyzed and compared by means of breakthrough studies. The breakthrough curves from the separation between $\mathrm{CO}_{2} / \mathrm{CH}_{4}$ (Fig. 5) and $\mathrm{CO}_{2} / \mathrm{N}_{2}$ (Fig. S8) binary mixtures. All of the breakthrough curves intensities are higher than the loaded concentration of $25 \%$, which is due to the strong adsorption of $\mathrm{CO}_{2}$ when it replaces $\mathrm{N}_{2}$ and $\mathrm{CH}_{4}$. The accessibility of the sponge-like material is better than the pristine SSZ-13 due to the presence of interconnected macropores which shortens the diffusion pathlength. The increase in accessibility is at the expense of separation performance. This result reveals the advantage of sponge-like structure which provides rapid access and effective use of intrinsic zeolite micropores.

\section{Conclusions}

In summary, we have synthesized SSZ-13 material in spongelike structure with great accessibility properties without compromising their intrinsic properties, which would bring substantial practical advantages. The sponge-like structure will bring benefits of rapid access and effective use of zeolite micropores and increasing the effective surface areas. This work demonstrated a simple and efficient route to develop sponge-like porous structure on a small pore zeolite, which could be extended to other zeolite materials.

\section{Conflicts of interest}

There are no conflicts to declare.

\section{Acknowledgements}

V.V. and Q.F. thank the National Natural Science Foundation of China (21571079, 21621001, 21390394, 21571076 and 21571078) for the financial support. S.M. and V.V. acknowledge the financial support from the CARNOT project ESP 3DNANOZET 5281.

\section{Notes and references}

1 C. Baerlocher and L. B. McCusker, http://www.izastructure.org/databases/.

2 A. M. Beale, F. Gao, I. Lezcano-Gonzalez, C. H. Peden and J. Szanyi, Recent advances in automotive catalysis for NOx emission control by small-pore microporous materials, Chem. Soc. Rev., 2015, 44, 7371-7405.

3 M. Yang, D. Fan, Y. Wei, P. Tian and Z. Liu, Recent Progress in Methanol-to-Olefins (MTO) Catalysts, Adv. Mater., 2019, 1902181, 1-15.

4 W. L. Dai, X. M. Sun, B. Tang, G. J. Wu, L. D. Li, N. J. Guan and $M$. Hunger, Verifying the mechanism of the ethene-topropene conversion on zeolite H-SSZ-13, J. Catal., 2014, 314, 10-20.

5 J. W. Jun, N. A. Khan, P. W. Seo, C. U. Kim, H. J. Kim and S. H. Jhung, Conversion of $Y$ into SSZ-13 zeolites and ethylene-topropylene reactions over the obtained SSZ-13 zeolites, Chem. Eng. J., 2016, 303, 667-674.

6 M. R. Hudson, W. L. Queen, J. A. Mason, D. W. Fickel, R. F. Lobo and C. M. Brown, Unconventional, highly selective $\mathrm{CO}_{2}$ adsorption in zeolite SSZ-13, J. Am. Chem. Soc., 2016, 134, 1970-1973.

7 T. D. Pham, Q. Liu and R. F. Lobo, Carbon dioxide and nitrogen adsorption on cation exchanged SSZ-13 zeolites, Langmuir, 2013, 29, 832-839.

8 A. M. Beale, F. Gao, I. Lezcano-González, C. H. F. Peden and J. Szanyi, Recent advances in automotive catalysis for $\mathrm{NO}_{x}$ emission control by small-pore microporous materials, Chem. Soc. Rev., 2015, 44, 7371-7405.

9 J. H. Kwak, D. Tran, S. D. Burton, J. Szanyi, J. H. Lee and C. H. F. Peden, Effects of hydrothermal aging on $\mathrm{NH}_{3}$-SCR reaction over Cu/zeolites, J. Catal., 2012, 287, 203-209.

10 Y. Tao, H. Kanoh, L. Abrams and K. Kaneko, MesoporeModified Zeolites: Preparation, Characterization, and Applications, Chem. Rev., 2006, 106, 896-910.

11 F. Gao, E. D. Walter, E. M. Karp, J. Luo, R. G. Tonkyn, J. H. Kwak, J. Szanyi and C. H. F. Peden, Structure-activity relationships in $\mathrm{NH}_{3}-\mathrm{SCR}$ over Cu-SSZ-13 as probed by reaction kinetics and EPR studies, J. Catal., 2013, 300, 20-29.

12 J. C. Groen, T. Sano, J. A. Moulijn and J. Perez-Ramirez, Alkaline-mediated mesoporous mordenite zeolites for acidcatalyzed conversions, J. Catal., 2007, 251, 21-27.

13 L. Mokrzycki, B. Sulikowski and Z. Olejniczak, Properties of Desilicated ZSM-5, ZSM-12, MCM-22 and ZSM-12/MCM-41 Derivatives in Isomerization of $\alpha$-Pinene, Catal. Lett., 2009, 127, 296-303.

14 C.-Y. Liu, US Pat., 4171242, 1979.

15 Z. Qin, K. A. Cychosz, G. Melinte, H. El Siblani, J.-P. Gilson, M. Thommes, C. Fernandez, S. Mintova, O. Ersen and V. Valtchev, Opening the Cages of Faujasite-Type Zeolite, J. Am. Chem. Soc., 2017, 139, 17273-17276.

16 Z. Qin, L. Pinard, M. A. Benghalem, T. Jean Daou, G. Melinte, O. Ersen, S. Asahina, J.-P. Gilson and V. Valtchev, Preparation of Single-Crystal 'House-of-Cards'-like ZSM-5 and Their Performance in Ethanol-to-Hydrocarbon Conversion, Chem. Mater., 2019, 31, 4639-4648.

17 Y. Kalvachev, T. Todorova and D. Nihtianova, H. Lazarova and M. Popova, Fluoride Etching of Mordenite and Its Influence on Catalytic Activity, J. Mater. Sci., 2017, 52, 5297-5308.

18 V. Valtchev, E. Balanzat, V. Mavrodinova, I. Diaz, J. E. Fallah, and J.-M. Goupil, High Energy Ion Irradiation-Induced 
Ordered Macropores in Zeolite Crystals, J. Am. Chem. Soc., 2011, 133, 18950-18956.

19 L. Tang, K.-G. Haw, Y. Zhang, Q. Fang, S. Qiu and V. Valtchev, Fast and efficient synthesis of SSZ-13 by interzeolite conversion of Zeolite Beta and Zeolite L, Micropor. Mesopor. Mater., 2019, 280, 306-314.

20 Z. Qin, G. Melinte, J.-P. Gilson, M. Jaber, K. Bozhilov, P. Boullay, S. Mintova, O. Ersen and V. Valtchev, The mosaic structure of zeolites, Angew. Chem. Int. Ed., 2016, 55, 1504915052.

21 M. Müller, G. Harvey and R. Prins, Comparison of the Dealumination of Zeolites Beta, Mordenite, ZSM-5 and Ferrierite by Thermal Treatment, Leaching with Oxalic Acid and Treatment with $\mathrm{SiCl}_{4}$ by ${ }^{1} \mathrm{H},{ }^{29} \mathrm{Si}$ and ${ }^{27} \mathrm{Al}$ MAS NMR, Micropor. Mesopor. Mater., 2000, 34, 135-147.

22 R. Baran, Y. Millot, T. Onfroy, J.-M. Krafft and S. Dzwigaj, Influence of the Nitric Acid Treatment on Al Removal, Framework Composition and Acidity of BEA Zeolite Investigated by XRD, FTIR and NMR, Micropor. Mesopor. Mater., 2012, 163, 122-130. 